\title{
The impact of digital technology on learning motivation and learning modes
}

\author{
Nadezhda Efremova* and Anastasia Huseynova \\ Don State Technical University, 344000, Rostov-on-Don, Russia
}

\begin{abstract}
The new era creates new opportunities and poses a number of challenges for education to adapt to the emerging prospects of digital transformation of educational activities. The article provides a brief analysis of domestic and foreign works on the problems of digitalization in education. It is shown that, along with the benefits offered by the digital space, there are many problems of its use in educational activities. The solution of these problems is primarily associated with the training of teachers to use new opportunities for the organization and implementation of distance learning forms, the development of their digital competencies. At the same time, it has been shown that in both foreign and domestic universities, students in their majority prefer contact forms of classes and want a live dialogue with teachers, despite their rather high digital literacy. Therefore, the emerging digital didactics is very important to determine the ratio of traditional and distance learning will be able to provide a comfortable learning environment and a high level of training of future specialists. These and other questions can be answered by digital didactics, which has not yet been developed by scientists and educational practitioners.
\end{abstract}

\section{Introduction}

Digital technology is increasingly embedded in our society, science, and education. This presents teaching with the challenges of determining how best to use the new possibilities to increase learning motivation and organize educational activities. It is clear that these technologies primarily attract and motivate young people to use various digital platforms and content. Therefore, previous forms of teaching may be considered outdated and inapplicable to the modern world by learners, losing motivation and interest as a value of learning. Today's generation of students seeks to learn differently than past generations, they have access to modern learning technologies on various platforms and a huge amount of the world's information through a variety of devices. This advantage becomes important if the educational activities are properly aligned with what is to be learned in mastering programs, course content, and internships. It is assumed that students who find information support in the learning process will be more motivated and feel included in the modern educational process $[1,2]$. Of course, in the new information environment pedagogy must change, relying on new principles, forms and techniques of educational activity in the new

*Corresponding author: nefremova61@donstu.ru 
environment. By integrating digital technologies and traditional forms of learning, teachers will be able not only to motivate students to intensify educational activity, but also to include in individualized forms of learning different categories of people, both with disabilities and gifted and talented.

It may be noted that digital pedagogy is now emerging in education, which should provide a scientifically sound application of digital technologies for classroom and independent work of students, to give answers to many questions. A distinctive feature of modern information tools is the ability to use them at any time and in any place, to find, copy, duplicate and apply the necessary information, quickly update and clarify it for each user.

Both external and internal factors influence the effectiveness of information use. External factors, such as standards, employer requirements, changing information environment, etc. They are caused by processes outside the educational system. However, their influence affects the development of educational programs and courses, the application of new forms of training, the principles of the educational process organization, ensuring the development of special methodological manuals and practices. Internal factors are related to the emotional state of students, their value orientations, satisfaction with educational activities, goal-setting and external support. With a positive impact, they get a sense of confidence in their abilities, self-esteem, the desire for self-development, the need for knowledge and reference to sources of information, including digital ones, develops. In this respect, the digital space is able to satisfy almost any needs.

The purpose of this study is to analyze and summarize the changes in the context of digital transformation and their impact on forms of learning and students' motivation for self-learning and self-development, taking into account the information capabilities of modern digital technology.

\section{Materials and methods}

This study examined the scientific literature on the problems of digital transformation in the global and domestic educational activities, the use of distance learning and its impact on the development of motivation in terms of wide availability of digital space information and educational platforms in the form of massive open online courses (MOOCs). A survey of students about their attitude to MOOCs was carried out.

\section{Results}

Goal orientation has a strong influence on persistence and the desire to complete a task, regardless of the level of difficulty. During the learning process, the learner experiences many different psychological states, such as surprise, confusion, anxiety, and helplessness or satisfaction. In all cases, individual motivation determines the actions with which he approaches the task, regardless of the attractiveness of a particular activity. Generally, complex activities require some support and strategies to increase motivation as an orientation to effective learning. Some works [3, 4] note that motivation increases with contact forms of learning, when there is an opportunity to communicate with peers and the teacher, to get to know other people, to receive an objective assessment of their achievements [5-7].

The use of digital tools creates certain challenges in the educational process, both for teachers and students. First of all, they must have digital skills and competencies. Not everyone is ready to make full use of digital technology yet. Despite the fact that digital technologies have great potential to positively influence the learning process, as practice 
shows, many students do not use them, so the potential of such technologies is not yet properly demanded $[8,9]$. At the same time, the digital space creates ample opportunities for students for self-study and self-education. The education system under such conditions becomes more flexible, democratic, open and accessible, regardless of the location of the student.

However, while the emergence of new technologies, while providing teachers with opportunities to create a variety of effective learning environments, many students prefer the traditional academic environment and contact forms of learning, despite the extensive use of social media in informal communication and the already existing digital literacy (Fig. 1).

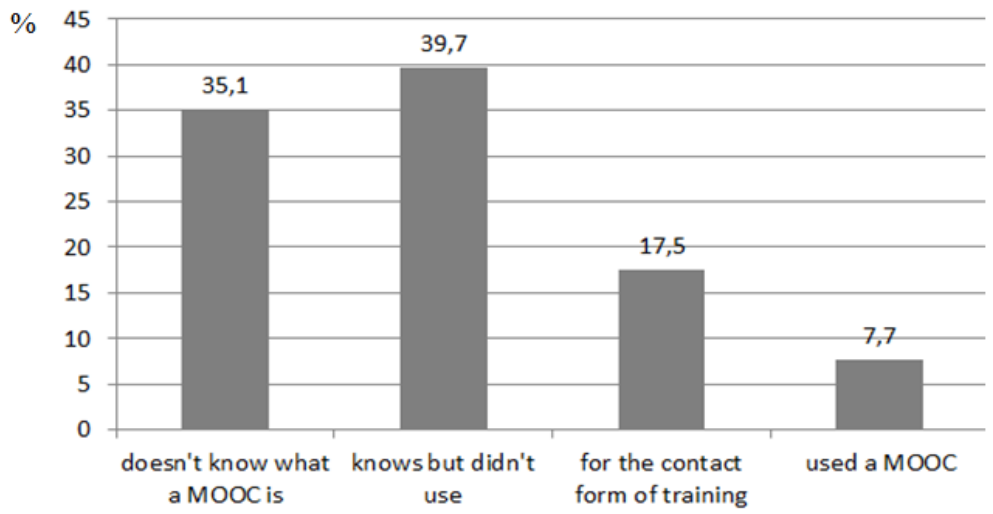

Fig. 1. Students' attitude towards MOOCs.

The use of digital technology in educational activities significantly changes the learning process, content and tools. All this requires appropriate equipment and technology. Digital learning methodology must be built on a thoughtful integration of different technologies, which is a rather complex task that requires too many variables to be considered, including the provision of certified online resources. Mixed forms of learning, flipped and individualized learning, relying on digital tools, are emerging. Inclusive education and adaptive learning are important uses of innovative educational technologies, for which digital technologies play a vital role. COVID-19 has accelerated the digital transition and highlighted the many challenges that accompany its implementation and the development of the education ecosystem.

According to international experts, digital technologies are most often used for ease of communication rather than to promote technologies for more effective pedagogy $[10,11]$. Of particular concern is the ambiguity of the impact of digitalization on the quality of fundamental and applied training of specialists and classical education. While an increasing number of jobs require some level of digital skills and digital competencies, such skills can be acquired and developed through informal curricula.

\section{Discussion}

Today there is a massive shift towards digital technologies, but there is still no clear vision of their effective use in education. Based on the generalization of the results of domestic $[12,13]$ and foreign Denmark and Norway [14], Ukraine [15], India [16, 17] studies, emphasis is made on the key possibilities of digitalization: the use in the educational process of virtual reality technologies and artificial intelligence, expanding the educational environment through mass open online courses, providing special conditions for individualization of learning. Some authors [18] point not only to the benefits of 
digitalization, but also to the difficulties (not the same accessibility to technology, reducing motivation and interest in learning "alone", etc.). Many articles express caution about the problem areas and risks of using new technologies based on the widespread use of digitalization. But at the same time attracted by the great opportunities of digital content, providing the creation of various technological environments, such as ecosystems and educational platforms, in which the learner can create for themselves the necessary technological, instrumental, methodological, documentary, partner, etc. space in order to solve their problems [19].

\section{Conclusion}

A brief review shows that for all the apparent benefits of digitalization in education so far has no scientific and pedagogical justification. There is little time for its active use in educational activities, the effectiveness of new pedagogical practices has not been proven and reliable results showing the impact on the structure of the traditional model of the educational process have not been obtained. There is still no evidence of a noticeable increase in learning motivation and improved learning outcomes, the consequences and impact of the technologies used on students' health are not clear. The possible loss of social skills is alarming. Disturbances in the authenticity of educational content from outside may also occur. It may be noted that the diversity of possibilities, contexts and conditions that digital technologies provide makes it difficult to identify clear and concrete actions and assess the implications for educational practice, it is not clear how well they contribute to supporting teaching and learning. There is a critical need today to identify the real-world challenges students face in taking online courses, to identify pedagogical approaches that address these challenges, and to increase the likelihood of successful online teaching and learning.

At the same time, the digital transformation of educational activities is already an objective reality, which in the future will increasingly enter all areas of public life. Therefore, comprehension of the extent to which new technologies can be used in educational activities, in what combination of contact and distance learning should be, to ensure the effectiveness of learning, scientists and practitioners still have to understand and provide methodological content of new forms of organization of training and control of its results. The formation of new pedagogical practices today is facilitated by three key phenomena: the digital generation of learners, the development of digital space and, most importantly, the digital economy and with its demands for the training of modern personnel. A new direction of pedagogical science - digital didactics - is still in its formative stage. With the dynamically changing demands of modern society, the requirements for graduates by employers are constantly updated, so new educational models must provide answers to the ever changing didactic learning objectives.

\section{References}

1. J. Francis, University of New England (2017).

2. J.L. Diedrich, The College at Brockport (2010).

3. T.B. Mikheeva, E.V. Murugova, SHS Web Conf. 70, 07003 (2018). doi: https://doi.org/10.1051/shsconf/20197007003

4. V.N. Minina, Bulletin of St. Petersburg University. Sociology 13 (1), 84-101 (2020). https://doi.org/10.21638/spbu12.2020.106 
5. F.P. Tulinayo, P. Ssentume, and R. Najjuma, International Journal of Educational Technology in Higher Education 15 (36), 1-19 (2018). Doi: org/10.1186/s41239-0180117-y

6. A. Belousova, V. Pishchik, International Journal of Cognitive Research in Science, Engineering and Education (IJCRSEE), Serbia 3 (2), 1-8 (2015).

7. N.F. Efremova, A.A. Huseynova, S. Shvedova, SHS Web Conf. 04003. ICTDPP-2019. (2019) DOI: doi.org/10.1051/shsconf/20197004003

8. N.F. Efremova, A.A. Khuseynova, Modern high Technologies 4, 164-169 (2020). DOI: 10.17513 / snt. 37992

9. N. Efremova, A. Huseynova, E3S Web of Conferences 175, 15015 (2020). https://doi.org/10.1051/e3sconf/202017515015

10. L.A. Burganova, Bulletin of Economics, Law and Sociology 4, 224-227 (2019).

11. A.R. Zenkov, Higher Education Problems 1, 52-55 (2020).

12. A.Yu. Uvarova, I. D. Frumin, Difficulties and Prospects of Digital Transformation of Education (HSE House, 2019).

13. A.A. Klimov, E.Yu. Zarechkin, V.P. Kupriyanovsky, Modern Information Technologies and IT-Education 15 (2), 468-476. doi: 10.25559/SITITO.15.201902

14. C.E. Tomte, T. Fossland, P.O. Aamodt, L. Degn, Quality in Higher Education 25 (1), 98-114 (2019). DOI: 10.1080/13538322.2019.1603611

15. O. Buinytska, B. Hrytseliak, Open educational e-environment of modern University (3), 6-16 (2017). DOI: 10.28925/2414-0325.2017.3.6ez16

16. S.Srivastava, R. Rai, H.K. Gupta, A. Yadav, H. Chandra, S. Baijal, International Journal For Research in Applied Science and Engineering Technology 6 (I), 26282637 (2018) DOI: 10.22214/ijraset.2018.1360

17. H.K. Dubey, A. Singh, S. Dubey, International Journal of Advance and Innovative Research 6(1(X)-1), 97-99. (2019).

18. K. Seethal, B. Menaka, International Journal for Research in Engineering Application \& Management. Special Issue. ICDOMP'19 140-143 (2019). DOI: 10.18231/24549150.2019 .0436

19. V.G. Khalin, G.V. Chernova, Advantages, Challenges, Threats and Risks. Management Consulting 10, 46-63 (2018). DOI 10.22394/1726-1139-2018-10-46-63 